\title{
New evidence for the Palaeolithic in Attica, Greece
}

\author{
Justin A. Holcomb ${ }^{1,2}$, Curtis Runnels ${ }^{1}$, Duncan Howitt-Marshall ${ }^{3}$, \\ Evangelos Sachperoglou ${ }^{4}$ \\ 1. Department of Archaeology, Boston University, Boston MA 02215, U.S.A. \\ Email: Holcomb: jholcomb@bu.edu; Runnels: runnels@bu.edu \\ 2. Malcolm H. Wiener Laboratory for Archaeological Science, American School of Classical Studies at Athens, \\ Souidias 54, Athens 10676, Greece. \\ 3. British School at Athens, Souidias 52, Athens 10676, Greece. Email: dshowittmarshall@gmail.com \\ 4. Kehagia 24, Filothei 15237 Athens, Greece. Email: esachp@otenet.gr
}

\begin{abstract}
:
Despite Greece's key geographic position between southeast Europe and southwest Asia, and its potential for documenting hominin dispersals, Lower and Middle Palaeolithic sites are rare. This suggests the need for research to identify deposits that may contain Palaeolithic artefacts. Here we describe 165 quartz and quartzite artefacts with Palaeolithic characteristics (based on technical and morphotypological definitions) from a private collection that was made from erosional lag deposits on the southeastern slopes of Mt. Pendeli and the northern edge of the Spata polje (a large karstic depression filled with terra rossas) in northeast Attica. Artefacts of the same type occur in the region of Ano Souli, another karstic depression. These karstic depressions are of interest because they resemble artefact-bearing deposits found at similar features such as Kokkinopilos in Epirus that have provided datable geologic contexts for Lower and Middle Palaeolithic artefacts. Our study suggests that Attica was frequented by hominins in the Lower and Middle Palaeolithic and that Pleistocene deposits in karstic depressions in Attica may preserve datable contexts for documenting early human activity. The lithic collection described here provides a glimpse of the potential of the region, and we recommend continued archaeological efforts in Attica to investigate the likelihood for buried Palaeolithic sites.
\end{abstract}

Keywords: Palaeolithic; hominin dispersal; quartz stone tools; Pleistocene; Attica; Greece

\section{Introduction}

Lower and Middle Palaeolithic sites in Greece are rare, particularly in the Middle Pleistocene. Renewed efforts over the last decade have begun to shed light on this time period (Tourloukis \& Harvati 2018), yet despite growing evidence for the importance of the Aegean Basin as a dispersal route for early hominins (Runnels 2014; Tourloukis \& Karkanas 2012), lithic assemblages associated with the Lower and Middle Palaeolithic have yet to be documented in Attica. Avocational archaeologist Evangelos Sachperoglou collected stone tools of Palaeolithic type from erosional lag deposits of rocks chiefly on the southeastern slopes of Mt. Pendeli and the northern edges of the Spata region of eastern Attica in 2015-

Published by the School of History, Classics and Archaeology, University of Edinburgh ISSN: 2055-0472. URL: http://journals.ed.ac.uk/lithicstudies/ 
2016 (Figure 1). These lag deposits are not sites in the sense of exposures of stratified deposits, geologic outcrops, or places of residence in the past, but resulted from downslope erosion. Despite this problem, several depositional settings were noted by our team to have the potential to contain such deposits. The collection was donated to the Ephorate [Directorate] of Palaeoanthropology and Speleology in Athens, and although these materials are not from archaeological sites per se, they indicate that sites or geologic outcrops may still be found in Attica. For this reason, coupled with the fact that Palaeolithic stone tools have not yet been documented in the region, we were granted permission by the Directorate of Prehistoric and Classical Antiquities of the Hellenic Ministry of Culture and Sports to evaluate and publish the finds to illustrate the potential for further Palaeolithic research in Attica. Unfortunately, most of the collection consists of natural stones, but we were able to identify 165 artefacts where the completeness of the artefact preserved recognizable technotypological characteristics. Notably, some of the stone tools were collected in the area of Ano Souli, a karstic depression (polje) containing Pleistocene terra rossas and palaeosols similar to the artefact-bearing deposits found at karstic depressions in Epirus, like Kokkinopilos (van Andel \& Runnels 2005; Runnels \& van Andel 2003; Tourloukis et al. 2015). Our study suggests that Lower and Middle Palaeolithic sites may also exist in northeast Attica, which, if confirmed by future research, would have implications for the migration of hominins in this region (see below).

\section{Methods}

The sample of artefacts for analysis was selected from about seven hundred pieces in the collection, the majority of which, however, were either natural stones or fragmentary and undiagnostic pieces of debitage. The sample selected for study comprises definite artefacts that are sufficiently complete to allow for the identification of their technomorphological features. Quartzite was used as a raw material, although the majority of the artefacts were made on vein quartz, which has been used for stone tool-making around the world, especially for thicker artefacts where specific methods of knapping were used to overcome the refractory tendency of quartz for fragmentation (Manninen 2016). The reflective surface of quartz makes it difficult to see flake removals, especially in direct incandescent or fluorescent light; therefore we used raking natural diffused light to discriminate flake removals from other surface features. For illustrating quartz artefacts we suggest the use of photorealistic models via photogrammetry (Figure 2) produced with software such as AgiSoft Photoscan Pro with the application of shaders in MeshLab to create 3D images to aid in interpreting patterns of flake removals (e.g., Magnani 2014; Vergne et al. 2010). Another added benefit of 3D scans is the ability to use 3D printers to manufacture copies for direct study (Olson et al. 2014). The classification of the quartz objects as artefacts was based on widely accepted criteria for distinguishing knapped tools (Shea 2013: table 3.2), requiring the presence of extensive symmetrical flake scarring, removal of most of the cortex, the presence of negative bulbs of percussion along multiple edges, and patterns or series of parallel or sub-parallel removals as evidence that the knapping was intended to shape the outline of the artefact. 


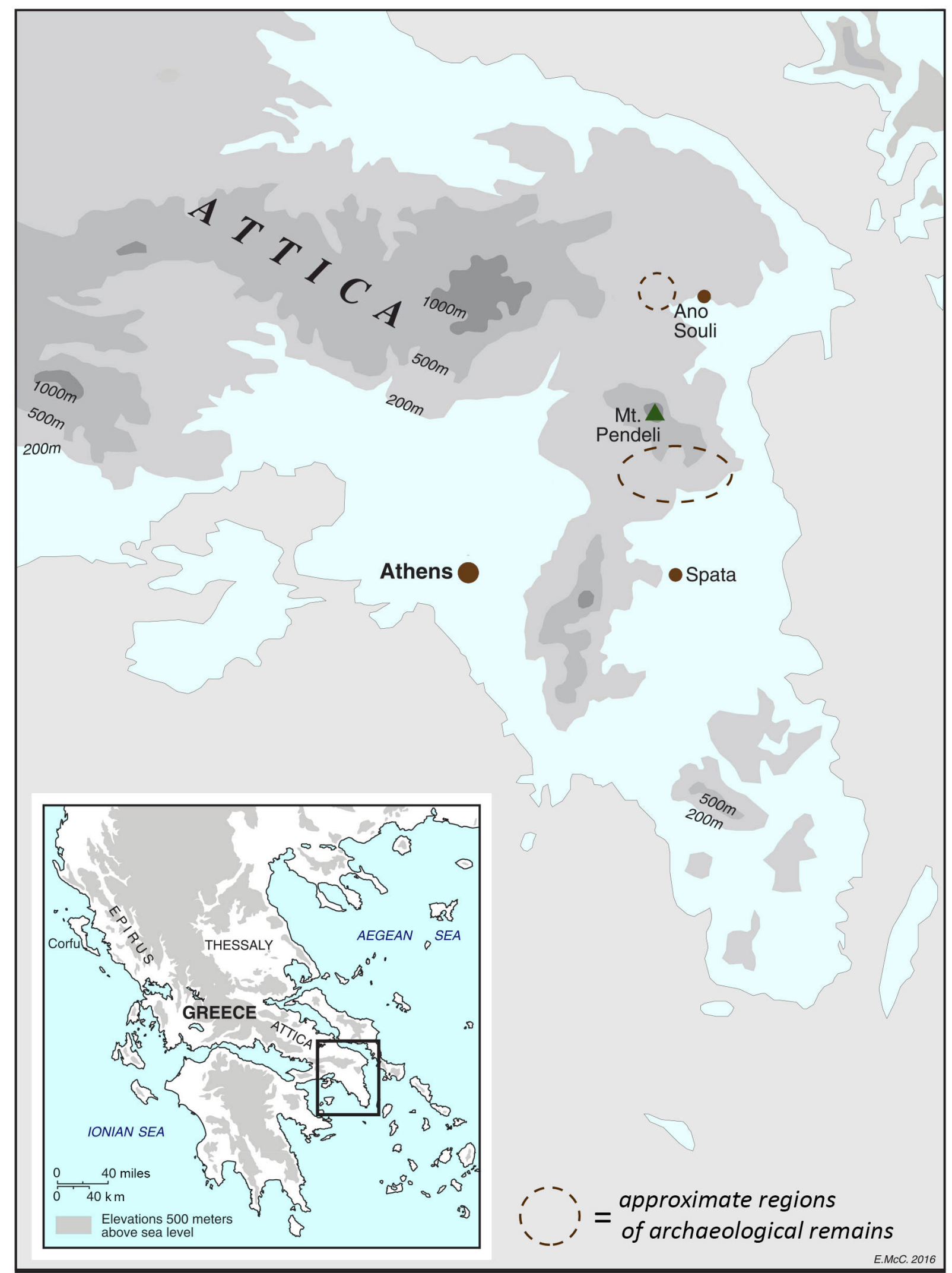

Figure 1. Approximate area where the collection of Palaeolithic stone artefacts was made. Map by Eliza McClennen. 

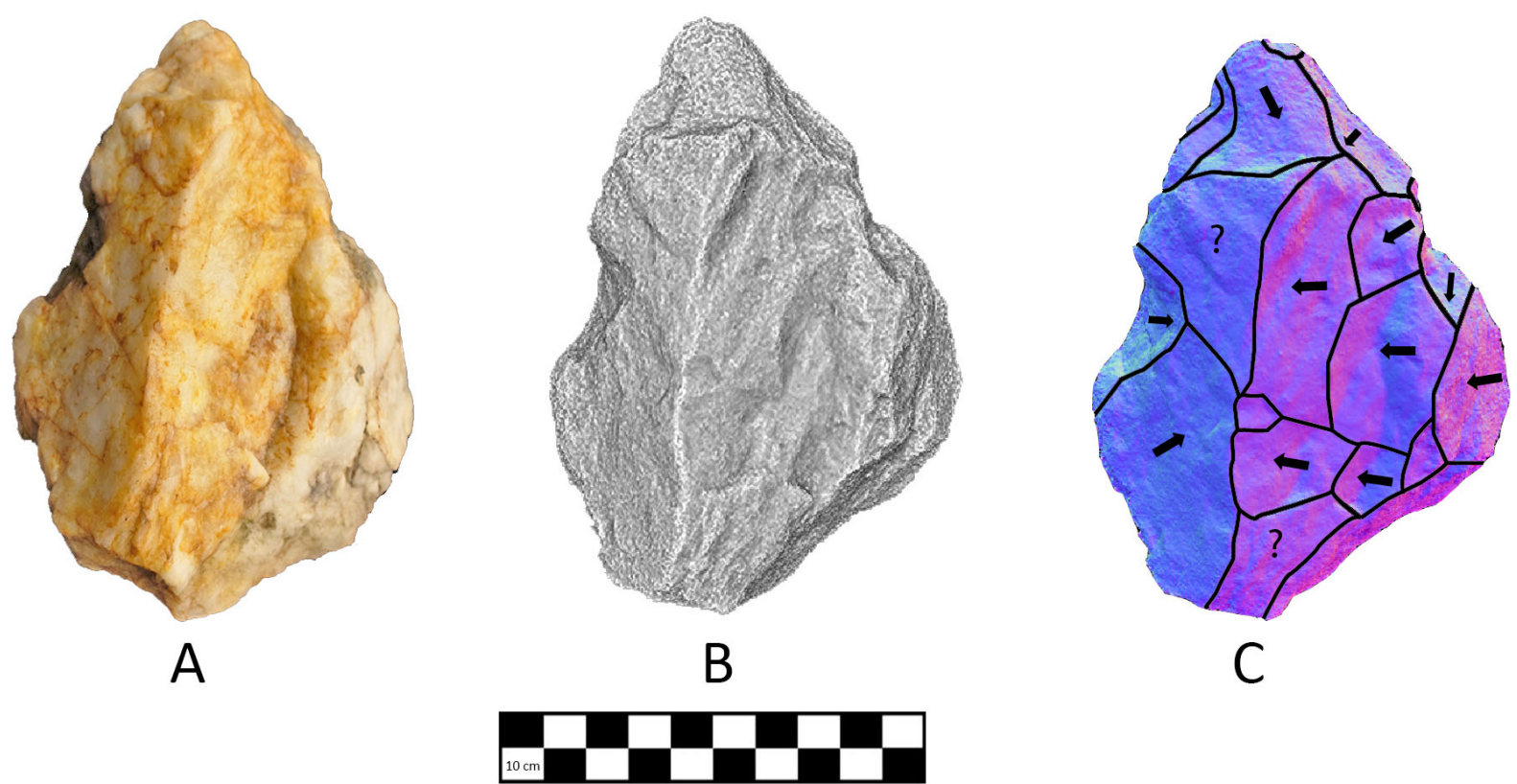

Figure 2. Handaxe (biface): A. photograph; B. photorealistic model with Radiance Scaling surface enhancement to reveal surface removals (Vergne et al. 2010); C. photorealistic model with normal shader with flake removal boundaries marked by black lines; arrows indicate the direction of flaking. Colours illustrate the distribution of light (blue = less light; red = more light) revealing undulating surfaces created by flake removals.

\section{Results}

Table 1 details the observed technotypological designations for the artefacts. Possible Lower Palaeolithic morphotypes were knapped by direct hard-hammer percussion and include pebble cores (chopping tools) and large cutting tools such as handaxes, cleavers, and picks. A massive scraper was also noted. Pebble cores have bifacial flaking defining one sinuous edge opposite an unworked or minimally-worked butt. The handaxes are large $(>10 \mathrm{~cm})$ core tools with two relatively straight edges converging to a distal tip; the handaxe subtypes are ovate to subtriangular in outline (Figure 3). Two handaxes were made on side-struck flakes, and seven were made on flakes where the axis of flaking is unknown. Other bifaces (cleavers, picks) were made on cobbles (where the original form can be recognized). Possible Middle Palaeolithic morphotypes include scrapers (end, déjété, single, and double sided), flakes from preferential cores, large blades $(>8 \mathrm{~cm})$ from preferential cores, and small cordiform handaxes (Figure 4). Possible Upper Palaeolithic morphotypes are end scrapers, burins, becs, and a perçoir. The artefacts are patinated and have reddish brown staining or red clay deposits on their surfaces. It is noteworthy that the patinas, weathering, staining, and deposits cover the flake removals, an indication that the tools are as old or older than the erosional lag deposits where they were found. The red staining and red clay may point to an original deposition in terra rossa. The artefacts also have unabraded edges suggesting minimal transport by lowenergy processes before their deposition within lag deposits, suggesting that any sites that remain are likely to be nearby.

\section{The Collection in Context}

In the absence of stratigraphic contexts, geologic associations, or radiometric dating, these lithic artefacts can be used for only one purpose, to suggest that Pleistocene deposits in this region, particularly large karstic depressions (poljes) filled with terra rossas and palaeosols such as those occurring at Ano Souli and Spata near the Venizelos International Airport (Figure 5), may preserve Palaeolithic remains. The red staining and clay on the artefacts certainly suggest that they were derived from such deposits, which are often 
associated with springs, wetlands, or seasonal lakes, where the sediments are rich in aeolian sand and can potentially be dated by luminescence dating, such as optically stimulated luminescence (OSL), infrared stimulated luminescence (IRSL), or post-IRSL, other radiometric methods such as uranium-series, and possibly by horizons of aeolian volcanic ash from Ischian eruptions (van Andel \& Runnels 2005; Runnels \& van Andel 2003; Tourloukis \& Karkanas 2012). In other areas in Greece, such as Epirus, these types of deposits have been dated to as early as 220,000 ka using IRSL (e.g., the site of Kokkinopilos; Tourloukis et al. 2015).

Table 1. The composition of the lithic collection in this study.

\begin{tabular}{lcc}
\hline Type & Number & Length (cm) \\
\hline Cores & & \\
Multidirectional & 9 & 6.6 \\
Recurrent Blade & 2 & 15.1 \\
Unidirectional Blade & 3 & 14.2 \\
Preferential flake & 9 & 7.3 \\
\hline Large Cutting Tools & & \\
Pebble core & 30 & 12.5 \\
Handaxe & 22 & 10.9 \\
Cleaver & 2 & 14.5 \\
Pick & 3 & 11.8 \\
Massive Scraper & 1 & 13.5 \\
\hline Flakes & & \\
Preferential & 2 & 6.7 \\
\hline Retouched Pieces & & \\
Burin & 5 & 6.6 \\
Bec & 9 & 9.5 \\
Scraper & 40 & 7.2 \\
Perçoir & 1 & 6.4 \\
\hline Technical Pieces & & \\
Blade & 8 & 10.3 \\
Miscellaneous & 19 & 9.5 \\
\hline Total & $\mathbf{1 6 5}$ & $\mathbf{1 1 . 6}$ \\
\hline
\end{tabular}

\section{Conclusions}

Our study suggests that Attica was frequented by hominins as early as the Middle Pleistocene and that geologic contexts in the region, particularly karstic depressions, may preserve datable associations with Palaeolithic artefacts. These data suggest that Attica was potentially a corridor at times in the Pleistocene leading to and from the Greek islands, including Crete, and should not be neglected in any study of early hominin dispersals. We call for future archaeological efforts in the region. We also suggest that research aimed at identifying archaeological sites and the assessment of the palaeogeography must consider the wider territory, incorporating the adjacent coastal lowlands and nearby islands. Underwater geoarchaeology, including seabed mapping, will no doubt add valuable data to this discussion and allow for a broader interpretation of Lower and Middle Palaeolithic archaeology in Attica. 


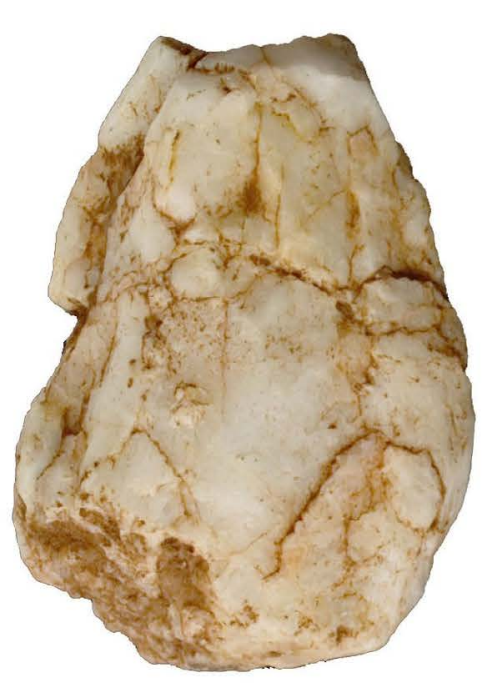

A
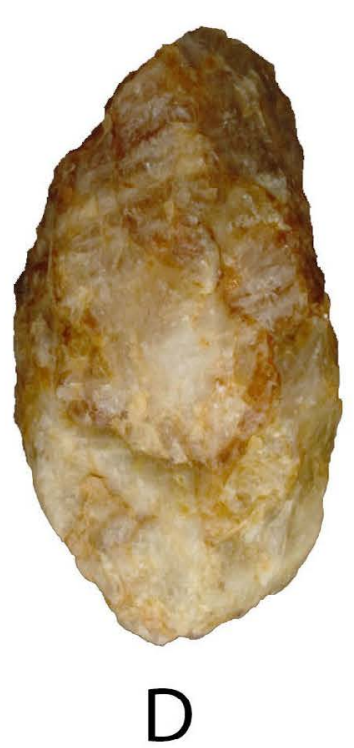

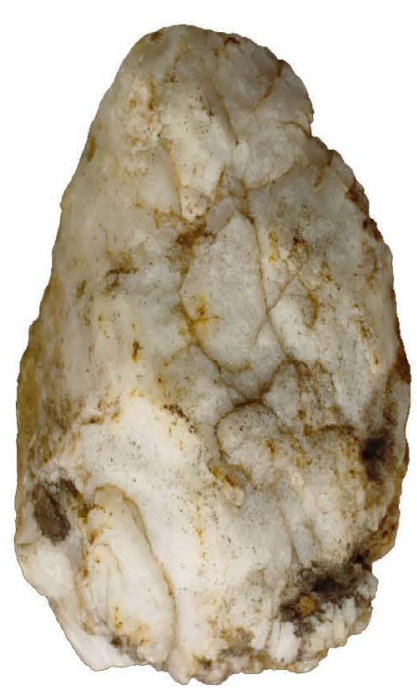

B

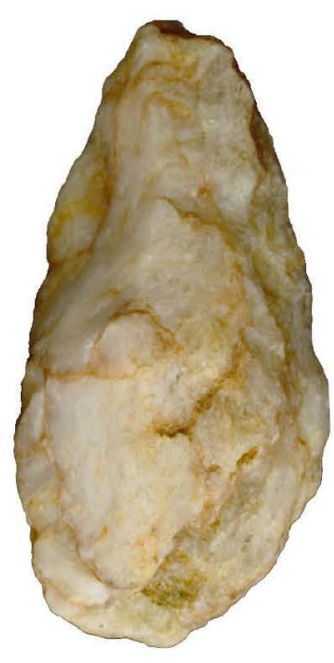

E

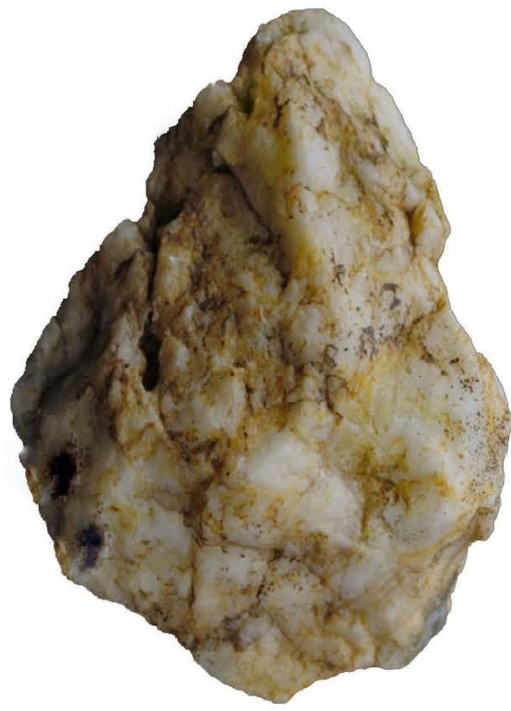

C

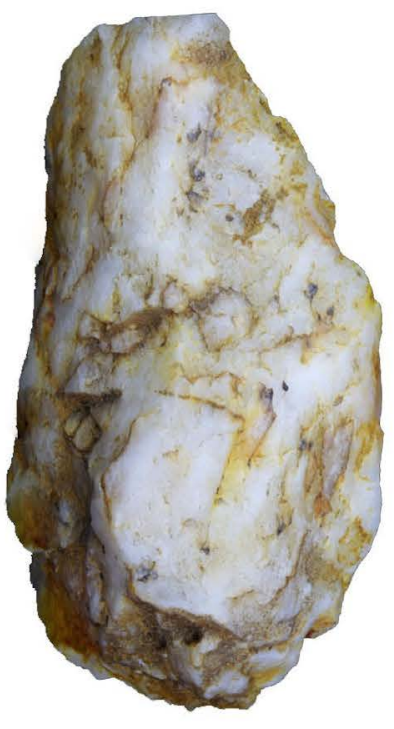

$\mathrm{F}$

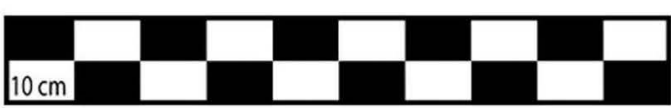

Figure 3. (A - F) A selection of handaxes (bifaces). The raw material is quartz. 


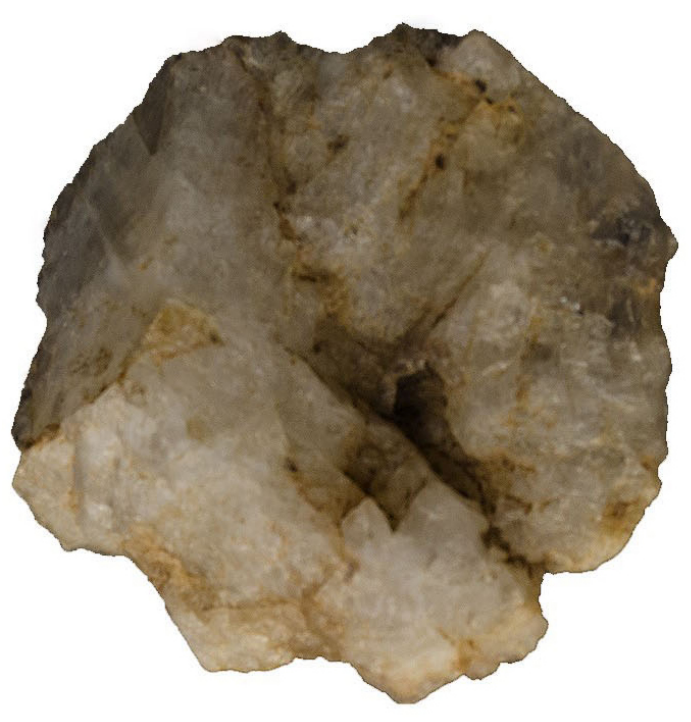

A

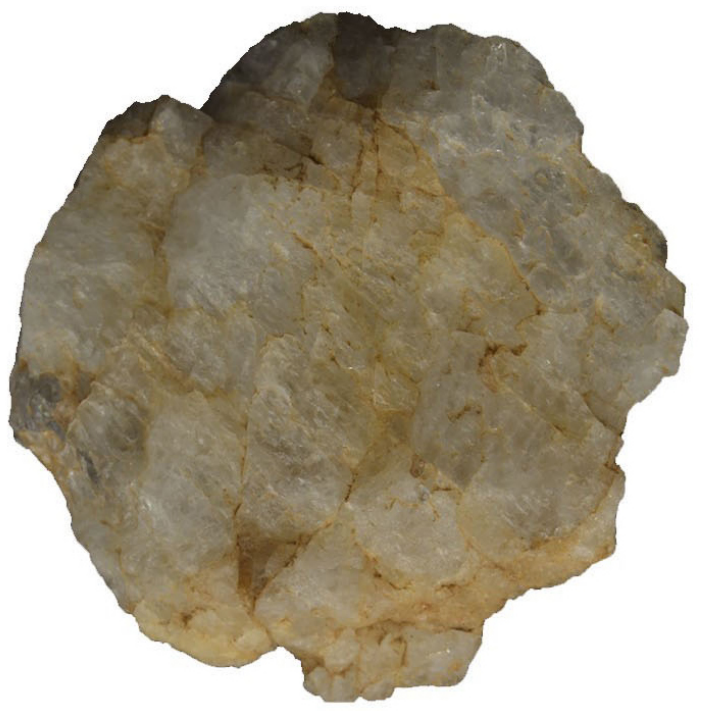

B

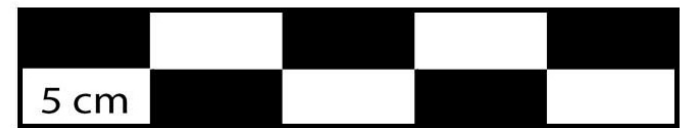

Figure 4. A discoidal preferential flake core. (A) dorsal and (B) ventral. The raw material is quartz.

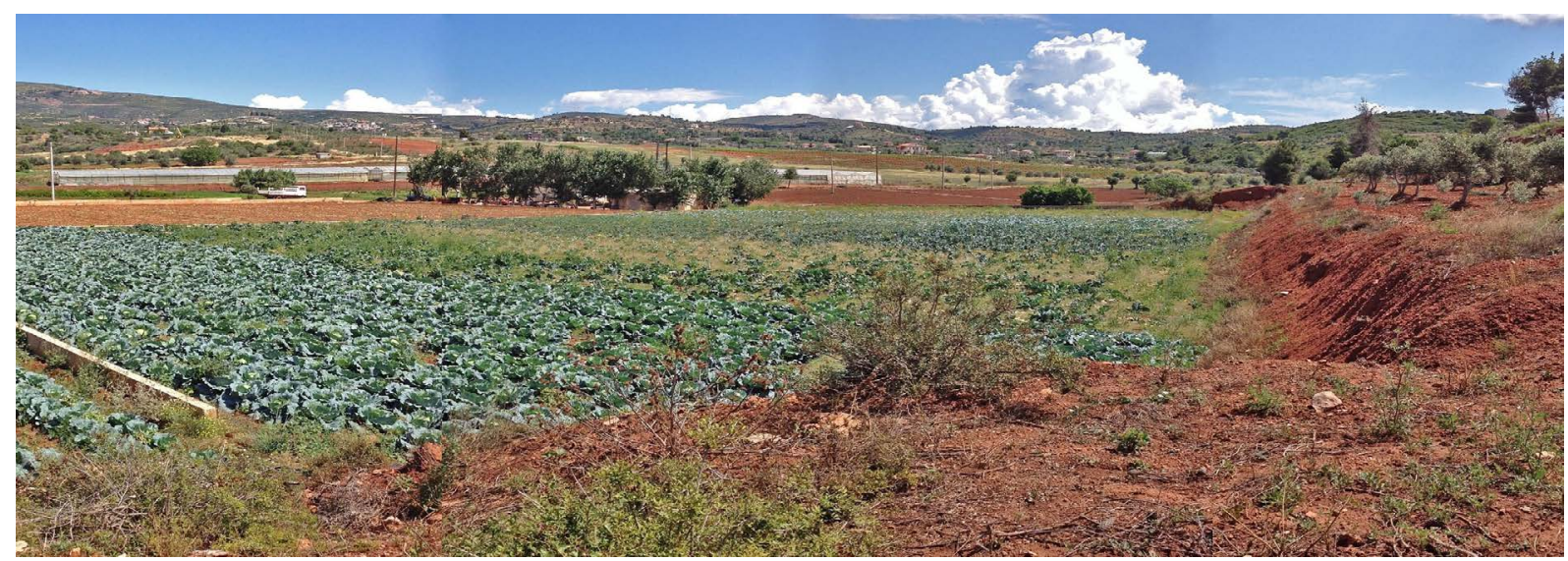

Figure 5. Polje (karstic depression) at Ano Souli with typical Pleistocene deposits rubefied by sub-aerial exposure.

\section{Acknowledgements}

We thank Dr. Eleni Panagopoulou of the Ephorate of Palaeoanthropology and Speleology, and the Directorate of Prehistoric and Classical Antiquities of the Hellenic Ministry of Culture and Sports for permission to study and publish this collection. We also thank the Institute of Aegean Prehistory and the Boston University Graduate School of Arts and Sciences for financial support. Finally, we thank the American School of Classical Studies at Athens and the Malcolm H. Wiener Laboratory of Archaeological Science for their support. This collection was donated to the Ephorate of Palaeoanthropology and Speleology and was studied under the permit protocol number [A.П.]: ППОА/ГААПК/АІПКА/ТЕЕАЕІ/186754/132643/4100/740 - Athens, 12/6/2018. 


\section{References}

van Andel, Tj. H. \& C. N. Runnels 2005, Karstic wetland dwellers of Middle Palaeolithic Epirus, Greece. Journal of Field Archaeology, 30: 367-384. doi:10.1179/009346905791072125

Magnani, M. 2014, Three-dimensional alternatives to lithic illustration. Advances in Archaeological Practice, 2(4): 285-297. doi:10.7183/2326-3768.2.4.285

Manninen, M. A. 2016, The effect of raw material properties on flake and flake-tool dimensions: a comparison between quartz and chert. Quaternary International, 424: 2431. doi:10.1016/j.quaint.2015.12.096

Olson, B. R., Gordon, J. M., Runnels, C. N. \& Chomyszak, S. 2014, Experimental threedimensional printing of a Lower Palaeolithic handaxe: an assessment of the technology and analytical value. Lithic Technology, 39: 162-172. doi:10.1179/2051618514Y.0000000004

Runnels, C. N. 2014, Early Palaeolithic on the Greek islands? Journal of Mediterranean Archaeology, 27(2), 211-230. doi:10.1558/jmea.v27i2.211

Runnels, C. N. \& van Andel, Tj. H. 1993, A handaxe from Kokkinopolis, Epirus, and its implications for the Palaeolithic of Greece. Journal of Field Archaeology, 20: 191-203. doi:10.1179/jfa.1993.20.2.191

Runnels, C. N. \& van Andel, Tj. H. 2003, The Early Stone Age of the Nomos of Preveza: Landscape and Settlement. In: Landscape Archaeology in Southern Epirus, Greece, (Wiseman, J. \& Zachos, K., Eds.), Vol. 32, American School of Classical Studies at Athens, Athens: p. 47-134. doi:10.2307/1354046

Shea, J. J. 2013, Stone Tools in the Palaeolithic and Neolithic Near East: A Guide. Cambridge University Press, Cambridge, 422 p. doi:10.1017/CBO9781139026314

Tourloukis, V. \& P. Karkanas. 2012, The Middle Pleistocene archaeological record of Greece and the role of the Aegean in hominin dispersals: new data and interpretations. Quaternary Science Reviews, 43: 1-15. doi:10.1016/j.quascirev.2012.04.004

Tourloukis, V., Karkanas, P., \& Wallinga, J. 2015, Revisiting Kokkinopilos: Middle Pleistocene radiometric dates for stratified archaeological remains in Greece. Journal of Archaeological Science, 57: 355-369. doi:10.1016/j.jas.2015.03.012

Tourloukis, V. \& Harvati, K. 2018, The Palaeolithic record of Greece: A synthesis of the evidence and a research agenda for the future. Quaternary International, 466: 48-65. doi:10.1016/j.quaint.2017.04.020

Vergne, R., Pacanowski, R., Barla, P., Granier, X. \& Schlick, C. 2010, Radiance scaling for versatile surface enhancement. In: Proceedings of the 2010 ACM SIGGRAPH symposium on Interactive 3D Graphics and Games, 19-21 February 2010. ACM, New York: p. 143-150. 